\title{
Genital warts in young Australians five years into national human papillomavirus vaccination programme: national surveillance data
}

\author{
(c) $\frac{(1)(8)}{\mathrm{gy}_{\mathrm{Na}}}$ OPEN ACCESS
}

\author{
Hammad Ali lecturer ${ }^{1}$, Basil Donovan professor ${ }^{12}$, Handan Wand senior lecturer ${ }^{1}$, Tim R H Read \\ sexual health physician ${ }^{34}$, David G Regan senior lecturer ${ }^{1}$, Andrew E Grulich professor ${ }^{1}$, Christopher \\ K Fairley professor ${ }^{34}$, Rebecca J Guy associate professor ${ }^{1}$
}

${ }^{1}$ The Kirby Institute, University of New South Wales, Sydney, NSW 2052, Australia; ${ }^{2}$ Sydney Sexual Health Centre, Sydney Hospital, Sydney, NSW 2000, Australia; ${ }^{3}$ Melbourne Sexual Health Centre, Carlton, VIC 3053, Australia; ${ }^{4}$ School of Population Health, University of Melbourne, Parkville, VIC 3010, Australia

\begin{abstract}
Objective To measure the effect on genital warts of the national human papillomavirus vaccination programme in Australia, which started in mid-2007.

Design Trend analysis of national surveillance data.

Setting Data collated from eight sexual health services from 2004 to 2011; the two largest clinics also collected self reported human papillomavirus vaccination status from 2009.

Participants Between 2004 and 2011, 85770 Australian born patients were seen for the first time; $7686(9.0 \%)$ were found to have genital warts.

Main outcome measure Rate ratios comparing trends in proportion of new patients diagnosed as having genital warts in the pre-vaccination period (2004 to mid-2007) and vaccination period (mid-2007 to the end of 2011).

Results Large declines occurred in the proportions of under 21 year old (92.6\%) and $21-30$ year old (72.6\%) women diagnosed as having genital warts in the vaccination period-from $11.5 \%$ in 2007 to $0.85 \%$ in 2011 $(P<0.001)$ and from $11.3 \%$ in 2007 to $3.1 \%$ in $2011(P<0.001)$, respectively. No significant decline in wart diagnoses was seen in women over 30 years of age. Significant declines occurred in proportions of under 21 year old (81.8\%) and 21-30 year old (51.1\%) heterosexual men diagnosed as having genital warts in the vaccination period-from $12.1 \%$ in 2007 to $2.2 \%$ in $2011(P<0.001)$ and from $18.2 \%$ in 2007 to $8.9 \%$ in $2011(\mathrm{P}<0.001)$, respectively. No significant decline in genital wart diagnoses was seen in heterosexual men over 30 years of age. In 2011 no genital wart diagnoses were made among 235 women under 21 years of age who reported prior human papillomavirus vaccination.

Conclusions The significant declines in the proportion of young women found to have genital warts and the absence of genital warts in vaccinated women in 2011 suggests that the human papillomavirus
\end{abstract}

vaccine has a high efficacy outside of the trial setting. Large declines in diagnoses of genital warts in heterosexual men are probably due to herd immunity.

\section{Introduction}

In 2007 Australia became one of the first countries to implement a nationally funded programme of quadrivalent human papillomavirus vaccination for girls and young women. ${ }^{1}$ The ongoing programme offers free vaccination to girls aged 12-13 years in schools. In addition, from 2007 to 2009 two catch-up programmes were implemented-one for 13-18 year old schoolgirls and the other for 18-26 year old women in the community. The quadrivalent vaccine provides protection against human papillomavirus types 6 and 11, which cause genital warts, in addition to the cancer causing types 16 and $18 .^{23}$ In 2010 the vaccination coverage rates in the school based programme were reported to be $83 \%$ for the first dose, $80 \%$ for the second dose, and $73 \%$ for the third dose in 12-13 year olds, ${ }^{4}$ with coverage rates decreasing with increasing age. The lowest rates of 52\% for the first dose in 20-26 year olds were observed in the community catch-up programme. ${ }^{45}$ Few men, or women who were over 26 years of age in 2007 , have been vaccinated. ${ }^{6}$ We established a sentinel surveillance network to monitor the effect of the vaccine on cases of genital warts seen at sexual health services across Australia. Earlier data from the network showed that two years after the vaccine was introduced the proportion of genital wart diagnoses declined by $59 \%$ in vaccine eligible young women aged 12-26 years in 2007 and by $39 \%$ in heterosexual men of the same age. ${ }^{6}$ No significant decline was observed in older women or men, non-resident young women, or men who have sex with men. ${ }^{6}$ In the same two year period, data from the Victorian cervical cytology registry 
showed a significant decrease in the incidence of high grade cervical abnormalities in girls aged under 18 years. ${ }^{7}$

In this study, we describe the ongoing population effect of the quadrivalent human papillomavirus vaccination programme on genital warts in Australian patients five years after the programme was established.

\section{Methods \\ Surveillance network}

Details of the surveillance network methods have been reported elsewhere. ${ }^{6}$ In summary, we recruited eight sexual health services dispersed across Australia that were able to provide retrospective data to 2004. Routine data on patients' demographics and behaviour (age, sex, country of birth, and gender of their sexual partners) and clinical diagnosis of genital warts were collated from all sites. In addition, the two largest clinics (Melbourne Sexual Health Centre and Sydney Sexual Health Centre) collected data on self reported human papillomavirus vaccination status of new patients from 2009 . This was a dichotomous question (yes/no) and did not record date of vaccination or number of doses of vaccine received.

\section{Data presentation}

Australian born patients who attended any of the services for the first time between January 2004 and December 2011 were included in the analysis. Men who reported having sex only with men or with both men and women in the previous 12 months were referred to as men who have sex with men, men who reported having sex with both men and women were referred to as bisexual, men who reported having sex only with men were referred to as homosexual, and men who reported having sex only with women were referred to as heterosexual. We divided the study period into the pre-vaccination period (from January 2004 to June 2007) and the vaccination period (from July 2007 to December 2011) on the basis of the vaccination programme starting in mid-2007. We calculated the proportion of patients diagnosed as having genital warts by dividing the total number of new diagnoses of warts by the total number of new patients seen. We stratified findings by age group at the time of presentation at the clinic: under 21 year olds-all women in this age group were eligible for the free vaccine at any time in the vaccination period; $21-30$ year olds - only a proportion of women in this age group were eligible for the free vaccine; and over 30 year olds-none of the women in this age group were eligible for the free vaccine at any time. We used the same age groups for heterosexual men, although none of these men were eligible for the free vaccine. For comparison, we calculated the proportion of Australian born patients who visited the eight services for the first time between 2004 and 2011 and tested positive for chlamydia.

\section{Statistical analysis}

We compared the proportion of patients diagnosed as having genital warts in the pre-vaccination and vaccination periods by using rate ratios and determined summary rate ratios along with 95\% confidence intervals over the eight year study period. Statistical significance was set at 0.05 . We used Stata version 12.1 to do all analyses and fit all models.

\section{Results}

Between 2004 and 2011, 85770 Australian born patients were seen for the first time at the eight sexual health services. Of these, $7686(9.0 \%)$ patients (2394 women and 5292 men) were diagnosed as having genital warts (table $1 \Downarrow$ ). Overall, the proportion of women diagnosed as having genital warts increased during the pre-vaccination period, from $8.9 \%$ in 2004 to $9.6 \%$ in 2007 , and then decreased in the vaccination period to $2.7 \%$ in 2011 . In men, the proportion remained relatively stable in the pre-vaccination period, from $12.8 \%$ in 2004 to $11.7 \%$ in 2007 , and then decreased in the vaccination period to $7.4 \%$ in 2011.

\section{Women under 21 years}

We found no significant trend in the proportion of under 21 year old women diagnosed as having genital warts in the pre-vaccination period $-8.8 \%$ in 2004 and $11.5 \%$ in 2007 $(\mathrm{P}=0.23)$. In the vaccination period, the proportion declined dramatically by $92.6 \%$, to $0.85 \%$ in 2011 with only 13 cases diagnosed $(\mathrm{P}<0.001)$ (fig $1 \Downarrow)$. The summary rate ratio comparing the vaccination period with the pre-vaccination period in these women was $0.64(\mathrm{P}<0.001)$ (table $2 \Downarrow)$.

Data from the two largest clinics showed that the proportion of under 21 year old women who reported being vaccinated had stabilised (71.7\% (246/343) reported being vaccinated in 2009 and $71.2 \%$ (235/330) in 2011). Notably, in 2011, among 235 women under 21 years of age who reported prior vaccination, none was found to have genital warts (upper end of $95 \%$ confidence interval 1.5\%). Furthermore, among 161 unvaccinated women aged under 21 in $2009-11$, only $7.3 \%$ (4/55) were found to have genital warts in 2011 (fig $2 \Downarrow$ ), compared with $10.5 \%$ in 2006 when all women were unvaccinated $(\mathrm{P}=0.14)$.

\section{Women aged 21-30 years}

We saw no significant decline in the proportion of 21-30 year old women diagnosed as having genital warts in the pre-vaccination period- $12.5 \%$ in 2004 and $11.3 \%$ in 2007 $(\mathrm{P}=0.89)$. In the vaccination period, the proportion declined by $72.6 \%$, to $3.1 \%$ in $2011(\mathrm{P}<0.001)$ (fig $1 \Downarrow)$. The summary rate ratio comparing the vaccination period with the pre-vaccination period in this age group was $0.81(\mathrm{P}<0.001)($ table $2 \Downarrow)$.

\section{Women over 30 years}

We saw no significant trend in the proportion of women aged over 30 years diagnosed as having genital warts either in the pre-vaccination period (from $3.8 \%$ in 2004 to $5.6 \%$ in 2007 ; $\mathrm{P}=0.07)$ or in the vaccination period $(4.4 \%$ in $2011 ; \mathrm{P}=0.99)$ (fig $1 \Downarrow$ ). The summary rate ratio comparing the vaccination period with the pre-vaccination period in this age group was $1.03(\mathrm{P}=0.48)($ table $2 \Downarrow)$.

\section{Heterosexual men under 21 years}

We found a significant increasing trend in the proportion of under 21 year old men diagnosed as having genital warts in the pre-vaccination period, with a $68.0 \%$ increase from $7.2 \%$ in 2004 to $12.1 \%$ in $2007(\mathrm{P}<0.01)$. In the vaccination period, the proportion declined dramatically by $81.8 \%$, to $2.2 \%$ in 2011 $(\mathrm{P}<0.001)$ (fig $3 \Downarrow)$. The summary rate ratio comparing the vaccination period with the pre-vaccination period in these men was $0.72(\mathrm{P}<0.001)($ table $2 \Downarrow)$.

\section{Heterosexual men aged $\mathbf{2 1 - 3 0}$ years}

We saw no significant decline in the proportion of 21-30 year old men diagnosed as having genital warts in the pre-vaccination period $-16.9 \%$ in 2004 and $18.2 \%$ in $2007(\mathrm{P}=0.32)$. In the 
vaccination period, the proportion declined by $51.1 \%$, to $8.9 \%$ in $2011(\mathrm{P}<0.001)$ (fig $3 \Downarrow)$. The summary rate ratio comparing the vaccination period with the pre-vaccination period in this age group was $0.88(\mathrm{P}<0.001)($ table $2 \Downarrow)$.

\section{Heterosexual men over $\mathbf{3 0}$ years}

We saw no significant trend in the proportion of men aged over 30 years diagnosed as having genital warts in either the pre-vaccination period (from $14.5 \%$ in 2004 to $11.1 \%$ in 2007; $\mathrm{P}=0.17)$ or in the vaccination period $(9.4 \%$ in $2011 ; \mathrm{P}=0.45)$ (fig $3 \Downarrow$ ). The summary rate ratio comparing the vaccination period with the pre-vaccination period in this age group was $0.97(\mathrm{P}=0.19)$ (table $2 \Downarrow)$.

\section{Men who have sex with men}

We saw no significant trend in the proportion of men who have sex with men diagnosed as having genital warts in the pre-vaccination period-9.0\% in 2004 and $8.5 \%$ in 2007 $(\mathrm{P}=0.11)$. In the vaccination period, the proportion declined by $24.7 \%$, to $6.4 \%$ in $2011(\mathrm{P}=0.04)$. The summary rate ratio comparing the vaccination period with the pre-vaccination period in men who have sex with men was $0.93(\mathrm{P}=0.01)$ (table $2 \Downarrow)$. In homosexual men, we saw a similar trend in both periods (summary rate ratio $0.92 ; \mathrm{P}<0.01$ ); in bisexual men, we saw no particular trend in either the pre-vaccination or vaccination period (summary rate ratio $1.01 ; \mathrm{P}=0.80$ ) (fig $4 \Downarrow$ ).

\section{Chlamydia}

We found no significant trend in the proportion of under 21 year old women $(\mathrm{P}=0.06)$, under 21 year old heterosexual men $(\mathrm{P}=0.43)$, and men who have sex with men $(\mathrm{P}=0.89)$ who tested positive for chlamydia in the pre-vaccination period. However, in the vaccination period a significant increase occurred in the proportion that tested positive for chlamydia in all three groups: under 21 year old women-37.8\% increase to $17.5 \%$ in 2011 $(\mathrm{P}<0.001)$; under 21 year old heterosexual men $-46.4 \%$ increase to $20.5 \%$ in $2011(\mathrm{P}=0.05)$; men who have sex with men-30.5\% increase to $7.7 \%$ in $2011(\mathrm{P}=0.03)$ (fig $5 \Downarrow)$. The summary rate ratios comparing the vaccination period with the pre-vaccination period were 1.19 for under 21 year old women $(\mathrm{P}<0.001), 1.58$ for under 21 year old heterosexual men $(\mathrm{P}<0.001)$, and 1.15 for men who have sex with men $(\mathrm{P}<0.08)$.

\section{Discussion}

This study shows that the proportion of young women diagnosed as having genital warts has continued to decline since the quadrivalent human papillomavirus vaccination programme started in Australia in 2007. Less than $1 \%$ of women aged under 21 years presenting at sexual health services were found to have genital warts in 2011, compared with $10.5 \%$ in 2006 before the vaccination programme started. By 2011, no genital warts were diagnosed in women aged under 21 who reported being vaccinated. A significant decline also occurred in genital wart diagnoses in 21-30 year old women, a trend not observed in older women. A similar pattern of declining diagnoses, but of a lesser magnitude, was seen in young heterosexual men.

\section{Strengths and limitations of study}

The major strength of this study is the inclusion of data from a range of services dispersed across the country, alleviating the concern about possible biases when data are reported from one service or one geographical location. The main limitation of the study is that sexual health services typically target populations that are at higher risk of sexually transmissible infections. In Australia, patients with symptoms are triaged into sexual health services, so these data represent a higher risk section of the population. Thus, a higher proportion of patients seen at sexual health services are expected to have genital warts than in the general population. That being said, the main purpose of this sentinel network was to evaluate trends, and, as shown in our analysis, a sharp decline in diagnoses has occurred in young women and men since the vaccination programme was rolled out in 2007. By contrast, our analyses showed that a significant increase occurred in the proportion of under 21 year old women, under 21 year old heterosexual men, and men who have sex with men who tested positive for chlamydia in the vaccination period (2007-11), suggesting that the decline in genital warts could not be attributable to the clinics seeing patients at lower risk.

\section{Possible explanations for findings}

The greatest decline in the proportion of women diagnosed as having genital warts was seen in the youngest age group (under 21 years), and all these women were eligible for the free quadrivalent human papillomavirus vaccine. A higher proportion of these women would have received the vaccine in school before becoming sexually active. ${ }^{4}$ The more modest decline in women aged 21-30 years reflects lower vaccine coverage. ${ }^{8}$ The proportion of women aged over 30 years with genital warts was low in the pre-vaccination period, as the peak age for developing genital warts is the late teens and early 20 s. ${ }^{9}$ No significant drop occurred in the proportion of diagnoses in these older women in the vaccination period, probably because they were ineligible for the free vaccine.

Our data show that genital warts may have disappeared in young women who reported being vaccinated. We were surprised by this finding, as some of these women probably had only one or two doses of vaccine, ${ }^{8}$ and false positive diagnoses are always possible. A randomised controlled trial of the quadrivalent human papillomavirus vaccine showed that the vaccine's efficacy as regards clinical disease associated with human papillomavirus 6 and 11 was $100 \% .{ }^{10}$ Historically, about $90 \%$ of cases of genital warts have been assumed to be attributable to human papillomavirus 6 and 11 . However, a recent study that analysed lesion tissues reported that $97 \%$ of genital warts were attributable to human papillomavirus 6 or $11 .^{11}$ Authors of this study point out that most studies use surface swabs to detect human papillomavirus DNA, with the potential that the detection may reflect carriage but not necessarily permissive viral growth. As no genital warts were detected in 2011 in young women vaccinated with quadrivalent human papillomavirus vaccine, it is possible that all cases of genital warts in Australia are attributable to human papillomavirus 6 and 11 (plus possibly human papillomavirus 16 and 18) or that the vaccine is providing cross protection against the other human papillomavirus types that cause warts. It will be interesting to see if this unexpected finding continues into the future and is replicated in other studies.

The decline in genital warts in the two younger age groups of heterosexual men can most likely be attributed to herd immunity, which is the indirect protection that unvaccinated people enjoy as a result of reduced exposure to infection. ${ }^{12}$ The decline was greater in men aged under 21 years compared with 21-30 year old men. The decline observed in genital warts in younger women in our study is in line with a published model of transmission of human papillomavirus 16 in Australia, which predicted a $60-100 \%$ decline in human papillomavirus 16 in 
vaccinated women with vaccination coverage of $80 \%$ of 12 year old girls. ${ }^{13}$

A modest but significant decline occurred in the proportion of men who have sex with men who were diagnosed as having genital warts in the vaccination period. This decline was not evident in bisexual men, so it is unlikely to be due to herd immunity resulting from the vaccination of women. The decline was limited to homosexual men who reported no female partners in the previous 12 months. This decline in the proportion of men who have sex with men diagnosed as having genital warts could be because the number of these men seen at the clinics increased between 2007 and 2011 (table $1 \Downarrow$ ). This confirms that asymptomatic men who have sex with men have been successfully triaged into sexual health services in Australia in recent years. ${ }^{14}$ This explanation is supported by data from the Sydney Sexual Health Centre, which reported that the positivity rates for sexually transmitted infections that are mostly symptomatic have decreased in men who have sex with men. ${ }^{15}$ It is also important to appreciate that men were classified into men who have sex with men, heterosexual, homosexual, or bisexual on the basis of the self reported sex of their partners in the previous 12 months. Some misclassification could be present due to the 12 months definition used.

\section{Comparison with other studies}

Findings from our study show a larger decline in young women and men than was seen in a recent study from Sweden, which reported an approximately $25 \%$ decline in incidence of genital warts in 17-18 year old women and no decline in men from 2006 to $2010 .{ }^{16}$ However, the quadrivalent human papillomavirus vaccine was not available free of cost in Sweden during this period; rather, it was commercially available at subsidised rates for girls aged 13-17 years only, leading to low coverage rates (25\% among 13-20 year olds for the first dose) compared with the high coverage rates observed in Australia. ${ }^{16}$ Similar findings were reported in female patients under 21 years of age presenting to family planning clinics in California, with a $35 \%$ decline between 2007 and 2010 (vaccine coverage rate in United States: 49\% among 13-17 year olds for first dose); a 19\% decline in male patients under 21 years of age was also reported. ${ }^{17}$ However, a study from Auckland sexual health service reported relatively larger declines: $63 \%$ decline in female patients under 20 years of age (vaccine coverage rates in Auckland: 52\% among female patients under 20 years) and a $40 \%$ decline in male patients under 20 years of age between 2007 and $2010 .{ }^{18}$

\section{Likely future trends}

In 2013, the Australian government started a publically funded programme in which 12-13 year old boys are eligible to receive free quadrivalent human papillomavirus vaccination through school based programmes. A catch-up programme provides free vaccination to $14-15$ year old boys for a two year period. ${ }^{19}{ }^{20} \mathrm{In}$ addition to preventing genital warts and anal, penile, and oropharyngeal cancer in men, the vaccination programme is expected to increase herd immunity and provide further indirect protection to unvaccinated women. ${ }^{21}$ The male quadrivalent human papillomavirus vaccination programme in addition to enhanced coverage rates in the female programme may lead to the control (defined as a reduction of disease incidence or prevalence to a locally acceptable level ${ }^{22}$ ), if not elimination, of the target human papillomavirus types in young people in Australia. Future monitoring using data from this network may confirm these expected benefits.
We thank the staff at the services that provided data for this study (Phillip Read, Heng Lu-Sydney Sexual Health Centre, Sydney, NSW; Stephen Davies, Amanda Rickett-Royal North Shore Hospital Sexual Health, Sydney, NSW; Nathan Ryder, Peter Knibbs—Darwin Clinic 34, Darwin, NT; Darren Russell, Colette Cashman—Dolls House Sexual Health Clinic, Cairns, QLD; Maree O'Sullivan, Stuart Aitken, Simon White-Gold Coast Sexual Health, Gold Coast, QLD; Louise Owen, Barb Lennox-Hobart Sexual Health Service, Hobart, TAS; Christopher Fairley, Marcus Chen, Afrizal Afrizal-Melbourne Sexual Health Centre, Melbourne, VIC; Lewis Marshall-Fremantle Hospital, Fremantle, WA) and CaraData for their help with data extraction.

Contributors: $B D, C K F$, and $A E G$ designed and were principal investigators of the study, with assistance from RJG and DGR. HA coordinated the surveillance network, collated data for this study, did the analysis with HW, and wrote the first draft. BD, RJG, THRR and CKF advised on analysis and interpretation. All authors contributed to the final report. $B D$ and $H A$ are the guarantors.

Funding: CSL Biotherapies funded the surveillance network but had no role in study design; data collection, analysis, or interpretation; or writing the report. Only the Kirby Institute had access to the study data, and the authors had sole responsibility of decision for publication.

Competing interests: All authors have completed the ICMJE uniform disclosure form at www.icmje.org/coi_disclosure.pdf (available on request from the corresponding author) and declare: CKF owns shares in CSL Biotherapies; CKF, AEG, DGR, RJG, and BD have received honorariums from CSL Biotherapies; $B D$ and RJG have received honorariums from Sanofi Pasteur MSD; BD, CFK, DGR, AEG, and RJG receive research funding from CSL Biotherapies; $B D, C F K$, and $A E G$ have received honorariums from Merck; $A E G$ sits on the Australian advisory board for the Gardasil vaccine; TRHR is a site investigator for a Merck human papillomavirus vaccine study.

Ethical approval: Ethical approval for the study was provided by the St Vincent's Hospital's ethics committee (EC00140) and the University of New South Wales ethics committee (EC00142). Further approval was provided by local research ethics committees of all sites.

Data sharing: Study protocol and data dictionary are available from the first author at hali@kirby.unsw.edu.au.

Garland SM, Skinner SR, Brotherton JML. Adolescent and young adult HPV vaccination in Australia: achievements and challenges. Prev Med 2011;53:S29-35.

2 Forster AS, Marlow LAV, Wardle J, Stephenson J, Waller J. Interest in having HPV vaccination among adolescent boys in England. Vaccine 2012;30:4505-10.

3 Olsson SE, Villa LL, Costa RLR, Petta CA, Andrade RP, Malm C, et al. Induction of immune memory following administration of a prophylactic quadrivalent human papillomavirus (HPV) types 6/11/16/18 L1 virus-like particle (VLP) vaccine. Vaccine 2007:25:4931-9.

4 Gertig DM, Brotherton JML, Saville M. Measuring human papillomavirus (HPV) vaccination coverage and the role of the National HPV Vaccination Program Register, Australia. Sex Health 2011;8:171-8.

5 Brotherton J, Gertig D, Chappell G, Rowlands L, Saville M. Catching up with the catch-up: HPV vaccination coverage data for Australian women aged 18-26 years from the National HPV Vaccination Program Register. Commun Dis Intell 2011;35:197.

6 Donovan B, Franklin N, Guy R, Grulich AE, Regan DG, Ali H, et al. Quadrivalent human papillomavirus vaccination and trends in genital warts in Australia: analysis of national sentinel surveillance data. Lancet Infect Dis 2011;11:39-44.

7 Brotherton JML, Fridman M, May CL, Chappell G, Saville AM, Gertig DM. Early effect of the HPV vaccination programme on cervical abnormalities in Victoria, Australia: an ecological study. Lancet 2011;377:2085-92.

8 Brotherton J, Deeks SL, Campbell-Lloyd S, Misrachi A, Passaris I, Peterson K, et al. Interim estimates of human papillomavirus vaccination coverage in the school-based program in Australia. Commun Dis Intell 2008;32:457-61.

9 Burchell AN, Winer RL, de Sanjosé S, Franco EL. Epidemiology and transmission dynamics of genital HPV infection. Vaccine 2006;24:S52-61.

10 Villa LL, Costa RLR, Petta CA, Andrade RP, Ault KA, Giuliano AR, et al. Prophylactic quadrivalent human papillomavirus (types $6,11,16$, and 18 ) $L 1$ virus-like particle vaccine in young women: a randomised double-blind placebo-controlled multicentre phase II efficacy trial. Lancet Oncol 2005;6:271-8.

11 Ball SLR, Winder DM, Vaughan K, Hanna N, Levy J, Sterling JC, et al. Analyses of human papillomavirus genotypes and viral loads in anogenital warts. J Med Virol 2011:83:1345-50.

12 Garnett GP. Role of herd immunity in determining the effect of vaccines against sexually transmitted disease. J Infect Dis 2005;191(suppl 1):S97.

13 Regan DG, Philp DJ, Hocking JS, Law MG. Modelling the population-level impact of vaccination on the transmission of human papillomavirus type 16 in Australia. Sex Health 2007;4:147-63.

14 Pedrana A, Hellard M, Guy R, El-Hayek C, Gouillou M, Asselin J, et al. Stop the drama downunder: a social marketing campaign increases HIV/sexually transmitted infection knowledge and testing in Australian gay men. Sex Transm Dis 2012;39:651-8. 


\section{What is already known on this topic}

Clinical trials have shown that the quadrivalent human papillomavirus (HPV) vaccine offers up to $100 \%$ protection against lesions caused by HPV 6 and 11

Declines in the incidence of genital warts have been documented in several countries, depending on the level of coverage with quadrivalent HPV vaccine

About $90 \%$ of cases of genital warts are generally thought to be due to HPV 6 and 11

\section{What this study adds}

In women, with $83 \%$ first dose vaccine coverage, a $93 \%$ decline in diagnosis of genital warts was seen by the fifth year of the national quadrivalent HPV vaccination programme in Australia

Despite men not being vaccinated, an $82 \%$ decline in genital warts occurred in heterosexual men, attributable to herd immunity No women who reported that they had been vaccinated were diagnosed as having genital warts in the final year of the study

15 Ryder N, Bourne C, Donovan B. Different trends for different sexually transmissible infections despite increased testing of men who have sex with men. Int J STD AIDS 2011;22:335-7.

16 Leval A, Herweijer E, Arnheim-Dahlström L, Walum H, Frans E, Sparén P, et al. Incidence of genital warts in Sweden before and after quadrivalent human papillomavirus vaccine availability. J Infect Dis 2012;206:860-6.

17 Bauer HM, Wright G, Chow J. Evidence of human papillomavirus vaccine effectiveness in reducing genital warts: an analysis of California public family planning administrative claims data, 2007-2010. Am J Public Health 2012;102:833-5.

18 Oliphant J, Perkins N. Impact of the human papillomavirus (HPV) vaccine on genital wart diagnoses at Auckland Sexual Health Services. J N Z Med Assoc 2011;124:51-8.

19 The Hon Tanya Plibersek MP Minister for Health Australia. HPV vaccine extended to boys. 2012. www.health.gov.au/internet/ministers/publishing.nsf/Content/mr-yr12-tp-tp059. htm.

20 Brill D. Australia launches national scheme to vaccinate boys against HPV. BMJ 2013;346:f924.
21 Australian Government Department of Health and Ageing. Fact sheet: National immunisation program—HPV vaccination for boys: Immunise Australia Program. 2012 (available from www.health.gov.au/internet/immunise/publishing.nst/Content/ 1958E18142193688CA2575BD001C80CA/\$File/HPV-vaccination-for-boys-factsheet.pdf). 22 Dowdle WR. The principles of disease elimination and eradication. MMWR 1999;48(SU01):23-7.

\section{Accepted: 14 March 2013}

\section{Cite this as: BMJ 2013;346:f2032}

This is an Open Access article distributed in accordance with the Creative Commons Attribution Non Commercial (CC BY-NC 3.0) license, which permits others to distribute, remix, adapt, build upon this work non-commercially, and license their derivative works on different terms, provided the original work is properly cited and the use is non-commercial. See: http://creativecommons.org/licenses/by-nc/3.0/. 


\section{Tables}

Table 1 Numbers of Australian born men and women diagnosed as having genital warts by numbers seen for first time at sexual health services, 2004-11

\begin{tabular}{|c|c|c|c|c|c|c|c|c|c|}
\hline & 2004 & 2005 & 2006 & 2007 & 2008 & 2009 & 2010 & 2011 & Total \\
\hline \multicolumn{10}{|l|}{ Women } \\
\hline Total & $377 / 4228$ & $387 / 3971$ & $404 / 4110$ & $433 / 4504$ & $247 / 4267$ & $233 / 4544$ & $189 / 4693$ & $124 / 4583$ & 2394/34 900 \\
\hline$<21$ years & $86 / 981$ & 92/908 & 100/956 & $127 / 1104$ & 70/1192 & $36 / 1288$ & $17 / 1451$ & $13 / 1525$ & $541 / 9405$ \\
\hline $21-30$ years & $240 / 1919$ & $235 / 1809$ & 238/1927 & $229 / 2028$ & $128 / 1810$ & $130 / 1924$ & $92 / 1971$ & $57 / 1840$ & $1349 / 15228$ \\
\hline$>30$ years & $51 / 1326$ & $59 / 1250$ & $66 / 1226$ & $77 / 1368$ & $49 / 1259$ & $67 / 1330$ & $80 / 1270$ & $54 / 1217$ & $503 / 10246$ \\
\hline \multicolumn{10}{|l|}{ Men } \\
\hline Total & $722 / 5620$ & $716 / 5596$ & $689 / 5667$ & $720 / 6173$ & $617 / 6246$ & $669 / 7158$ & $641 / 7437$ & $518 / 6973$ & $5292 / 50870$ \\
\hline Heterosexual, total & $554 / 3715$ & $548 / 3590$ & $530 / 3427$ & $547 / 3773$ & $463 / 4013$ & $519 / 4658$ & $463 / 4934$ & $375 / 4671$ & 3999/32 781 \\
\hline$<21$ years & $23 / 321$ & $20 / 280$ & $42 / 301$ & $47 / 387$ & $30 / 492$ & $33 / 686$ & $14 / 784$ & $16 / 731$ & 225/3982 \\
\hline $21-30$ years & $275 / 1627$ & $311 / 1664$ & $291 / 1582$ & $318 / 1744$ & $285 / 1892$ & $301 / 2151$ & $254 / 2297$ & $194 / 2190$ & $2229 / 15147$ \\
\hline$>30$ years & $256 / 1765$ & $217 / 1646$ & $197 / 1544$ & $182 / 1641$ & $148 / 1628$ & $185 / 1821$ & $195 / 1853$ & $165 / 1749$ & $1545 / 13647$ \\
\hline Men who have sex with men, total & $126 / 1394$ & $140 / 1463$ & $109 / 1490$ & $134 / 1568$ & $114 / 1538$ & $120 / 1807$ & $146 / 1986$ & $117 / 1826$ & $1006 / 13072$ \\
\hline Homosexual & $100 / 1102$ & $114 / 1149$ & $86 / 1189$ & $115 / 1234$ & $92 / 1214$ & $101 / 1493$ & $121 / 1589$ & $93 / 1489$ & $822 / 10459$ \\
\hline Bisexual & 26/292 & $26 / 314$ & $23 / 301$ & $19 / 334$ & $22 / 324$ & $19 / 314$ & $25 / 397$ & $24 / 337$ & $184 / 2613$ \\
\hline
\end{tabular}


Table 2| Average annual trends in diagnosis of warts at sexual health services with summary rate ratios, 2004-11

\begin{tabular}{|c|c|c|c|c|c|c|}
\hline \multirow[b]{2}{*}{ Group } & \multicolumn{2}{|c|}{ Pre-vaccination period ${ }^{*}$} & \multicolumn{2}{|c|}{ Vaccination period $^{*}$} & \multicolumn{2}{|c|}{ Pre-vaccination $v$ vaccination period } \\
\hline & $\begin{array}{l}\text { Average annual trend } \\
\qquad(95 \% \mathrm{Cl})\end{array}$ & $P$ value & $\begin{array}{l}\text { Average annual trend } \\
\qquad(95 \% \mathrm{Cl})\end{array}$ & $P$ value & $\begin{array}{c}\text { Summary rate ratio }(95 \% \\
\mathrm{Cl})\end{array}$ & $P$ value \\
\hline \multicolumn{7}{|l|}{ Women: } \\
\hline$<21$ years & $1.10(0.95$ to 1.26$)$ & 0.232 & 0.50 (0.45 to 0.55$)$ & $<0.001$ & 0.64 (0.59 to 0.69$)$ & $<0.001$ \\
\hline $21-30$ years & $1.00(0.91$ to 1.09$)$ & 0.891 & 0.74 (0.70 to 0.79$)$ & $<0.001$ & 0.81 (0.77 to 0.85$)$ & $<0.001$ \\
\hline$>30$ years & 1.18 (0.99 to 1.42$)$ & 0.071 & 1.00 (0.93 to 1.08$)$ & 0.993 & $1.03(0.96$ to 1.10$)$ & 0.485 \\
\hline \multicolumn{7}{|l|}{ Heterosexual men: } \\
\hline$<21$ years & $1.44(1.10$ to 1.87$)$ & 0.007 & $0.61(0.54$ to 0.70$)$ & $<0.001$ & 0.72 (0.65 to 0.81$)$ & $<0.001$ \\
\hline $21-30$ years & $1.04(0.96$ to 1.13$)$ & 0.316 & $0.84(0.81$ to 0.87$)$ & $<0.001$ & $0.88(0.85$ to 0.91$)$ & $<0.001$ \\
\hline$>30$ years & 0.94 (0.85 to 1.03$)$ & 0.168 & 0.98 (0.94 to 1.03$)$ & 0.448 & $0.97(0.93$ to 1.01$)$ & 0.193 \\
\hline $\begin{array}{l}\text { Men who have sex } \\
\text { with men: }\end{array}$ & 0.90 (0.80 to 1.02$)$ & 0.109 & 0.94 (0.89 to 0.99 ) & 0.041 & 0.93 (0.89 to 0.99$)$ & 0.012 \\
\hline Homosexual & 0.90 (0.78 to 1.03$)$ & 0.127 & 0.92 (0.87 to 0.98$)$ & 0.011 & $0.92(0.87$ to 0.97$)$ & 0.003 \\
\hline Bisexual & $0.93(0.70$ to 1.23$)$ & 0.593 & $1.03(0.91$ to 1.19$)$ & 0.590 & $1.01(0.90$ to 1.15$)$ & 0.797 \\
\hline
\end{tabular}

*Pre-vaccination period=1 January 2004 to 30 June 2007; vaccination period=1 July 2007 to 31 December 2011. 


\section{Figures}

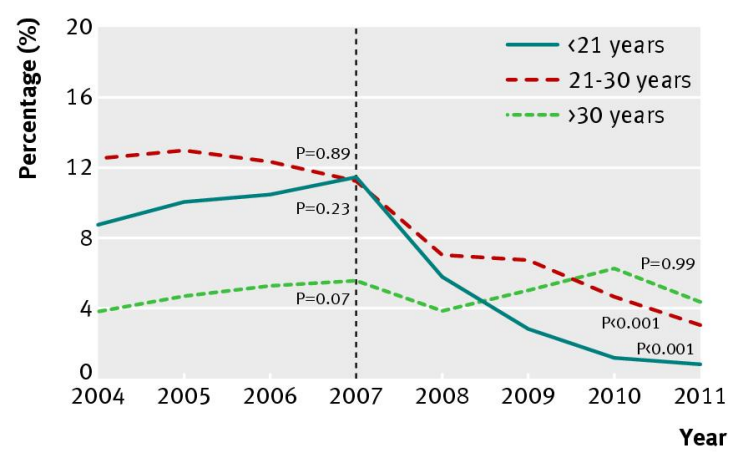

Fig 2 Proportion of Australian born women aged under 21 years diagnosed as having genital warts at first visit to Sydney and Melbourne Sexual Health Centres, by vaccination status, 2009-11. Numbers are number diagnosed as having genital warts/number seen

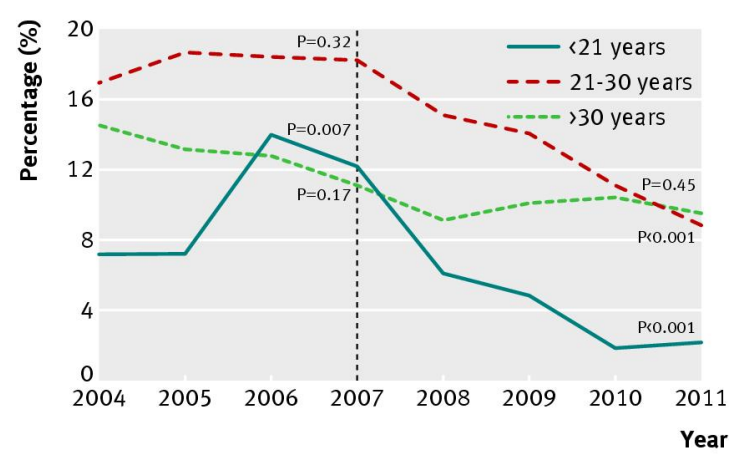

Fig 3 Proportion of Australian born heterosexual men diagnosed as having genital warts at first visit, by age group, 2004-11 


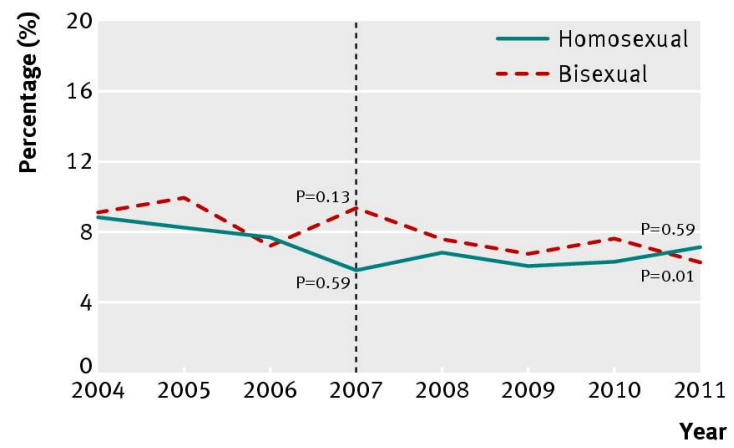

Fig 4 Proportion of Australian born homosexual and bisexual men diagnosed as having genital warts at first visit, 2004-11

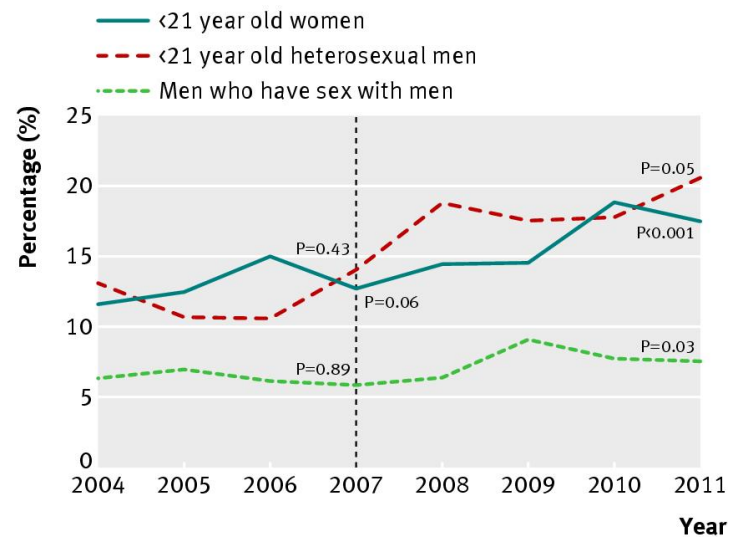

Fig 5 Proportion of Australian born women aged under 21 years, heterosexual men aged under 21 years, and men who have sex with men who tested positive for chlamydia at first visit, 2004-11 